\title{
EL ACCESO A LA INFORMACIÓN AMBIENTAL EN ESPAÑA A LA LUZ DE LA NUEVA LEY DE TRANSPARENCIA*
}

\author{
Alejandro Corral Sastre \\ Profesor Colaborador Doctor de Derecho Administrativo en la Universidad CEU San Pablo \\ de Madrid - España. E-mail: alejandro.corralsastre@ceu.es.
}

Resumo: Após a promulgação da lei espanhola de transparência, acesso à informação e boa governança, o caminho para acesso à informação ambiental não mudou. Temos agora uma lei geral e uma lei específica (direito de acesso à informação, participação pública e acesso à justiça ambiental), que é aplicada em prioridade. Ambas as regulações têm diferenças importantes que são analisadas nesse trabalho.

Palavras-chave: Transparência. Acesso à informação. Informação ambiental. Lei geral. Lei específica. Análise comparativa.

Sumário: 1 Introducción - $\mathbf{2}$ Nota introductoria sobre el Derecho Medioambiental - $\mathbf{3}$ Marco jurídico internacional en materia de acceso a la información ambiental - $\mathbf{4}$ El reconocimiento del derecho de acceso a la información ambiental en el derecho de la Unión Europea - $\mathbf{5}$ Marco constitucional del derecho de acceso a la información ambiental - $\mathbf{6}$ El derecho de acceso a la información ambiental a la vista de la aprobación de la nueva Ley de Transparencia. Análisis comparativo de ambas regulaciones - 7 Conclusiones - Referencias

\section{Introducción}

En el Boletín Oficial del Estado del 10 de diciembre del año 2013,1 aparece publicada la tan deseada Ley 19/2013, de 9 de diciembre, sobre transparencia, acceso a la información pública y buen gobierno (en adelante me referiré a ella como Ley de Transparencia o ley de transparencia general). Cuestión diferente

* Este trabajo se elabora en el marco del Proyecto I+D Ref. DER 2012-35948 sobre "Protección de Datos y Aplicación extraterritorial de las normas. La reforma de la Directiva sobre protección de datos" del que es investigador principal el Prof. José Luis Piñar Mañas.

1 El 10 de diciembre del año 2013 se publicaron, junto con la Ley de Transparencia ya mencionada, otras dos leyes de importancia capital para el ordenamiento jurídico español: la Ley 20/2013, de 9 de diciembre, de garantía de la unidad de mercado, y la Ley 21/2013, también de 9 de diciembre, de evaluación ambiental. Este tridente normativo es una buena muestra de los cambios jurídicos de fondo que se están llevando a cabo en el Derecho español en los últimos años. 
es, como inmediatamente pondré de manifiesto, si esta Ley cumple con las expectativas generadas en la sociedad española a lo largo de los últimos años.

Adelanto ya que no. El profesor José Luis Piñar Mañas, lo ha puesto de manifiesto en diferentes conferencias en las que ha participado como ponente desde su publicación, indicando que es una norma "manifiestamente mejorable". ${ }^{2}$ Algo con lo que estoy totalmente de acuerdo.

Pero, al margen de las innegables críticas que se puedan hacer a la reciente Ley de Transparencia, el objeto de este trabajo es algo más restringido. Pretendo analizar, como se indica en el título, como queda la regulación del derecho de acceso a la información ambiental, regulada en la Ley $27 / 2006$, de 18 de julio, por la que se regulan los derechos de acceso a la información, de participación pública y de acceso a la justicia en materia de medio ambiente, después de la aprobación de la Ley de Transparencia.

Esta cuestión no carece de importancia porque desde el momento en que se publica la Ley de Transparencia, de carácter general, se hace imprescindible estudiar en qué medida afecta a la regulación sectorial previa y como se engranan ambas regulaciones. De modo y manera que pueda comprobarse si existen contradicciones entre ambas leyes y, de ser así, cual prevalece.

Desde este momento se ha de indicar que la materia medioambiental tiene una serie de características propias que la hacen acreedora de una mayor rigurosidad, si cabe, en materia de transparencia y acceso a la información. Si estas son necesarias, como se verá, en general, para garantizar el desenvolvimiento de un Estado Democrático (artículo 1.1 de nuestra Constitución Española), permitiendo el ejercicio del derecho a la participación (artículo 23 de la Constitución), o a la información (artículo 20 de la misma Norma), en materia medioambiental se hacen imprescindibles habida cuenta de que la ausencia de una información adecuada o la eliminación de las correspondientes vías de participación pueden afectar directamente a la salud o integridad física de las personas, disminuyendo su calidad de vida e impidiendo el libre desarrollo de su personalidad.

Este dato va a resultar crucial. Existe una íntima relación entre el derecho de acceso a la información y la participación, por un lado, y la protección del medio ambiente junto con la garantía de una mínima calidad de vida, por otro. De tal forma que en esta materia en concreto no solo están en juego los derechos fundamentales antes referidos de participación pública e información (artículos

2 Sin ánimo de ser exhaustivo, el profesor Piñar Mañas se ha referido a la Ley de Transparencia en estos términos en el Seminario del maestro García de Enterría que se celebró el miércoles 14 de mayo de 2014 en Departamento de Derecho Administrativo de la Facultad de Derecho de la Universidad Complutense de Madrid, o en la conferencia de Letrados de Comunidades Autónomas realizado el martes 23 de mayo en el Salón de Grados de la Universidad CEU San Pablo de Madrid. 
20 y 23 de la Constitución Española), sino también otros derechos como son el de la dignidad de la persona y el libre desarrollo de la personalidad (artículo 10) o incluso el derecho a la vida e integridad física y moral (artículo 15). En este sentido se puede hablar de la dimensión ambiental de los derechos fundamentales, ya reconocida por la jurisprudencia del Tribunal Europeo de Derechos Humanos desde la famosa sentencia en el caso López Ostra contra España de 9 de diciembre de 1994. ${ }^{3}$ Esta dimensión ambiental debe tenerse en cuenta en nuestro ordenamiento jurídico, como es sabido, por mor del artículo 10.2 de la Constitución Española. ${ }^{4}$

\section{Nota introductoria sobre el Derecho Medioambiental}

No nos podemos remontar a los orígenes del moderno Derecho Ambiental porque ocuparía demasiado espacio y, además, no es el objeto de este trabajo. Pero debe hacerse referencia a que este Derecho, como conjunto de normas relativas a la protección del medio ambiente, es un Derecho muy reciente que nace a mediados del siglo pasado, después de la Segunda Guerra Mundial, cuando los estados comienzan a percatarse de que los recursos naturales no son infinitos y que un deterioro excesivo del medio ambiente puede llevar a poner en riesgo la propia existencia del ser humano sobre nuestro planeta.

En relación al contenido de la protección del medio ambiente, se debe indicar que es una materia muy compleja, debido principalmente a la amplitud de los fines que persigue. $Y$ es que, lo que sea considerado protección del medio ambiente va a resultar esencial para determinar la normativa aplicable en materia de acceso a la información y transparencia. Si estamos ante materia ambiental, se aplicará

3 Aunque existen casos anteriores como por ejemplo el caso Arrondelle contra Reino Unido en la década de los ochenta, o el caso Powell y Rayner contra Reino Unido en el año 1990. Véase en este sentido a DE SALES CAVEDÓN, F., en “La construcción de una dimensión ambiental de los derechos humanos por la jurisprudencia de la Corte Europea de Derechos Humanos: el derecho de acceso a la información y a la libertad de expresión en materia ambiental" Revista Aranzadi de derecho ambiental, 2008, núm. 14, p. 137-155. Sobre la jurisprudencia del Tribunal Europeo de Derechos Humanos, véase BOUAZZA ARIÑO, O., en "Respeto a la vida privada y protección del medio ambiente en la jurisprudencia del Tribunal Europeo de Derechos Humanos", Revista de Administración Pública, núm. 160, 2003. También BOUAZZA ARIÑO, O., "Vías indirectas para la protección del medio ambiente", Revista de Administración Pública, núm. 170, 2006. BOUAZZA ARIÑO, O., "Constitutional Environnmental Rights", Revista de Administración Pública, núm. 169, 2006. En el mismo sentido BOUAZZA ARIÑO, O., "Tribunal Europeo de Derechos Humanos: derechos frente a la contaminación, libertad de conciencia ambiental y protección urbanística del suelo" en LÓPEZ RAMÓN, F. (Coord.) Observatorio de políticas ambientales 2013. s: el derecho de acceso a la infnos por la jurisprudencia de la Corte Europea de Derechos Humanos: el derecho de acceso a la inf

4 MARTín RETORTILlo BAQUER, L., La Europa de los Derechos Humanos, Centro de Estudios Políticos y Constitucionales, Madrid, 1998; MARTíN RETORTILLO BAQUER, L., Vias concurrentes para la protección de Ios derechos humanos. Madrid: Civitas, 2006; LOZANO CUTANDA, B. Derecho Ambiental Administrativo. 9. ed. Madrid: Dykinson, 2008, pág. 81 y 82. 
la Ley 27/2006, de 18 de julio, de carácter sectorial. Por el contrario, si estamos ante una materia que no está relacionada con la protección del medio ambiente, se aplicará la Ley general de transparencia. Lo difícil será, por consiguiente, determinar si estamos ante una materia ambiental o no. Y es que la protección del medio ambiente tiene un amplio espectro de proyección: desde la protección de la atmosfera, pasando por los mares y las aguas continentales, hasta las masas forestales y, por supuesto, la flora, la fauna y la biodiversidad. Y estos solo como ejemplo sin ánimo de ser exhaustivo, por supuesto.

A la vista de lo anterior, se debe señalar que el Derecho medioambiental presenta una serie de características especiales que podemos resumir en tres:

- Se trata de un Derecho transversal. Es decir, cualquier decisión tomada, política pública implementada o norma jurídica aprobada, independientemente de que no se refiera directamente a la materia, afectará, si quiera indirectamente, al medio ambiente.

- Es un Derecho muy complejo. Complejidad derivada, esencialmente, de la gran cantidad de finalidades que persigue.

- Nos encontramos ante un Derecho de ámbito internacional o supranacional. Debemos de tener en cuenta, en este sentido, que el hecho de que un Estado adopte medidas eficaces para la protección del medio ambiente, no impedirá graves atentados al mismo si el país vecino no adopta unos mínimos instrumentos de protección. La contaminación y los daños medioambientales no conocen fronteras, de ahí que deba adoptarse una perspectiva internacional del problema. ${ }^{5}$

\subsection{Los principios del Derecho Medioambiental}

Para un jurista, hablar de principios jurídicos debe ser una cuestión que no se puede tomar a la ligera. Debemos ser especialmente rigurosos cuando nos referimos a ellos, pues no solo son considerados fuente del ordenamiento jurídico, sino que, en su vertiente quizás más relevante, sirven como criterios de interpretación al resto del ordenamiento. Así lo pone de manifiesto el artículo 1.4 de nuestro Código Civil.

5 Esta perspectiva internacional la comparte el Derecho medioambiental con el Derecho de las tecnologías de la información y de las comunicaciones. Sin una visión internacional del problema, con una perspectiva exclusivamente nacional o local, no se logrará el cumplimiento de los objetivos marcados por el propio Derecho en orden a garantizar la protección suficiente de los bienes jurídicos correspondientes. 
Por ello, cuando me refiero a los principios generales del Derecho medioambiental, me siento obligado a manifestar que estos no nacen de manera espontánea en el ordenamiento jurídico como si brotaran, de repente, de un manantial que nace con las recientes y copiosas lluvias. Muy al contrario, estamos ante unos principios que aparecen más bien como sedimentos después del largo recorrido a lo largo de un rio de aprobaciones normativas, aplicaciones e interpretaciones por los diferentes operadores jurídicos. Algo así como el resultado de un largo proceso de decantación jurídica que da lugar a estos principios generales.

En este sentido, y teniendo en cuenta todo lo anterior, podemos indicar que los principios jurídicos del Derecho medioambiental, según la doctrina más cualificada ${ }^{6}$ son los siguientes:

- Necesidad de lograr un alto nivel de protección. Exigencia que proviene del grado de deterioro que en la actualidad sufre nuestro medio ambiente. Solo con un altísimo nivel de protección podremos mantener un medio ambiente adecuado y una mínima calidad de vida.

- Acción preventiva y de cautela. ${ }^{7}$ Resulta necesario poner de manifiesto que, en materia ambiental, es preferible actuar antes de que el daño se produzca, adoptando todas las medidas necesarias para impedir su consecución. ${ }^{8}$ Siempre será más eficaz evitar un riesgo que actuar para corregirlo. En este sentido cabe señalar que, en medio de una corriente liberalizadora que pretende llevar a cabo una sustitución generalizada de los sistemas de control administrativo previo (autorizaciones y licencias), por los controles llamados posteriores (comunicaciones previas y declaraciones responsables), la protección del medio ambiente sigue considerándose como una razón imperiosa de interés general que justifica

LOZANO CUTANDA, B., Derecho Ambiental Administrativo, cit., págs. 188 a 195, La profesora LOZANO se refiere a estos principios como principios de la acción comunitaria ambiental, pero desde luego, cumplen la función señalada de principios generales del Derecho, sobre todo teniendo en cuenta que desde la aprobación del Tratado de Funcionamiento de la Unión Europea, la protección del medio ambiente es una competencia compartida entre la Unió y los Estados miembros (artículo 4). En el mismo sentido, FERNÁNDEZ VALVERDE, R., "La integración de las exigencias del Convenio de Aarhus en el sistema procesal español a través de la Ley 27/2006", en LOZANO CUTANDA, B.; GUTIERREZ-ALVIZ CONRADI, F. (Dirs.). Examen de la nueva ley de acceso a la información, participación pública y acceso a la justicia en materia de medio ambiente, Estudios de Derecho Judicial, núm. 137, Consejo General del Poder Judicial, Madrid, 2008, págs. 42 a 44.

7 Para que esta acción preventiva y de cautela sea lo más eficaz posibles se utilizan instrumentos tales como la Evaluación de Impacto Ambiental o la Evaluación Ambiental Estratégica, instrumentos ambos recogidos en la reciente Ley $21 / 2013$, de 9 de diciembre, de evaluación ambiental.

8 No obstante, para evitar el riesgo habrá que conocer, según el estado de la ciencia y de la técnica, la potencialidad del daño y, por tanto, adoptar los medios más eficaces que impidan la producción del mismo. Resultan especialmente interesantes, en este sentido, las reflexiones realizadas por el profesor ESTEVE PARDO, J., en El desconcierto del Leviatán. Madrid: Marcial Pons, 2009. 
el mantenimiento de los tradicionales sistemas de control previo, mucho más eficaces. ${ }^{9}$

- Corrección de los atentados al medio ambiente preferiblemente en la fuente misma. Este principio responde a la misma filosofía preventiva del anterior. Lo más eficaz, en este sentido, es tratar los atentados al medio ambiente desde el mismo lugar donde se producen, o lo más próximo posible, para evitar su extensión.

- Principio de "quien contamina paga". Como fácilmente puede deducirse, este principio implica que quien debe hacerse cargo de los gastos por los daños al medio ambiente, así como el restablecimiento de las cosas a su estado original, en la medida de lo posible, será aquel que los haya ocasionado, es decir, el agente contaminante. Este principio se ha desarrollado en el uso de instrumentos económicos y fiscales que gravan a las empresas más contaminantes.

- Transversalidad de la protección del medio ambiente. A este principio ya nos hemos referido como una de las características propias del Derecho medioambiental. Sin embargo se debe hacer especial hincapié en el mismo, pues resulta esencial que la protección del medio ambiente sea tenida en consideración en el desarrollo de cualquier política pública, aprobación normativa o decisión de los diferentes Poderes públicos.

Si nos paramos un minuto a reflexionar sobre los principios del Derecho medioambiental que acabamos de mencionar, podemos llegar a la conclusión, sin demasiado esfuerzo, de que esos mismos principios se pueden aplicar en materia de protección de datos con los correspondientes e imprescindibles matices, por su supuesto.

Así, también se debe reclamar de los correspondientes Poderes públicos un alto nivel de protección de este derecho fundamental, impidiendo vulneraciones no deseadas del mismo. La protección de datos es una materia transversal u horizontal, es decir, debe tenerse en cuenta a la hora de desarrollar otras políticas públicas, o la aprobación de normas jurídicas, de cualquier rango, o la toma de

9 Desde la aprobación de la Directiva 2006/123/CE, del Parlamento Europeo y del Consejo, de 12 de diciembre, relativa a los servicios en el mercado interior, se impone a todos los Estados miembros la eliminación de controles previos que no cumplan los requisitos señalados en la norma (no discriminación, necesidad y proporcionalidad). En España esta norma ha sido desarrollada por la Ley 17/2009, de 23 de noviembre, sobre el libre acceso a las actividades de servicios y su ejercicio, también conocida como "Ley Paraguas", y la Ley 25/2009, de 22 de diciembre, de modificación de diversas leyes para su adaptación a la Ley sobre el libre acceso a las actividades de servicios y su ejercicio, o como algunos la han denominado, "Ley Ómnibus". Nuestro país ha avanzado en la senda liberalizadora, más allá de lo que exigía la mencionada Directiva comunitaria, mediante la aprobación de otras leyes como la Ley 2/2011, de 4 de marzo, de Economía Sostenible, o la más reciente Ley 20/2013, de 9 de diciembre, de garantía de la unidad de mercado. 
decisiones. En otras palabras, la protección de datos debe impregnar con su aroma todo el ordenamiento jurídico y la actuación de los diferentes Poderes públicos. ${ }^{10}$

Por otro lado, también respecto del derecho de protección de datos es deseable una acción preventiva y de cautela, más eficaz que la que pueda realizarse después de la producción del daño. Desde esta perspectiva resulta especialmente interesante los instrumentos para evaluar el impacto a la privacidad (PIA's, en sus siglas en inglés de Privacy Impact Assessment) que son definidos como "Herramientas de valoración sistemática del riesgo a la privacidad integrada en el proceso de toma de decisión de una organización", contribuyendo con ello al Privacy by design o Privacy by default, es decir, tomar en cuenta la protección de datos desde el minuto cero, previendo los riesgos. ${ }^{11}$

También es esta materia resulta especialmente importante la circunstancia de quién debe hacerse responsable de los daños producidos por vulneraciones al derecho de protección de datos. En este sentido cabe referir el principio de Accountability o responsabilidad, asimilado al principio ambiental de "quien contamina paga".

Por último, en relación a la corrección de los daños ambientales desde la fuente mismo para impedir que puedan extenderse, podemos ver una íntima relación con los principios de Privacy by design o Privacy by default ya mencionados, es decir, atajar los posibles daños desde la fuente misma del riesgo.

\section{Marco jurídico internacional en materia de acceso a la información ambiental}

Una de las principales características del derecho internacional del medio ambiente es que ha venido recogido, con carácter general, en instrumentos programáticos (o de soft law), algo que implica una menor eficacia frente a

10 Sobre estas características del derecho a la protección de datos, véase PIÑAR MAÑAS, J. L., "El derecho a la protección de datos de carácter personal en la jurisprudencia del Tribunal de Justicia de las Comunidades Europeas", Derecho contencioso-administrativo: libro homenaje al profesor Luis Henrique Farias Mata, BADELL MADRID, R. (Coord.). Instituto de Estudios Jurídicos del Estado de Lara. PIÑAR MAÑAS, J. L., “derecho fundamental a la protección de datos personales. Algunos retos de presente y futuro", Revista parlamentaria de la Asamblea de Madrid, núm. 13, 2005. PIÑAR MAÑAS, J. L. "La protección de datos”, CANO CAMPOS, T., (Coord.). Lecciones y materiales para el estudio del derecho administrativo, v. 9, Madrid: lustel, 2009.

11 Sobre estos instrumentos de evaluación de impacto de la privacidad, me resultó especialmente esclarecedora la ponencia del Profesor Joaquín Pérez Catalán del viernes 28 de marzo de 2014 en el Master Universitario de Protección de Datos, Transparencia y Acceso a la información que se imparte en la Universidad CEU San Pablo de Madrid. Recientemente se ha publicado un borrador de "Guía para una evaluación de impacto en la protección de datos personales" por la Agencia Española de Protección de Datos, que puede consultarse en la página web de esta Agencia, <www.agpd.es>. 
instrumentos con plena potencia jurídica (hard law), con la fuerza necesaria para imponer consecuencias jurídicas negativas a los Estados incumplidores. Esta es una de las principales debilidades del derecho internacional en la actualidad (en general, y el referido a la protección del medio ambiente en particular), como ha puesto de manifiesto algún autor, ${ }^{12}$ aunque, poco a poco, van apareciendo medidas tendentes a paliar estas circunstancias, como bien a señalado el profesor Schmidt-Assman, E., al indicar que "Ias fronteras de los espacios administrativos se vuelven permeables. Cada nueva cooperación amplía las posibilidades de actuación administrativa, pero desvincula progresivamente a las Administraciones implicadas de sus mecanismos de dirección y control tradicionales". ${ }^{13}$ Es decir, esta internacionalización tiende a solventar problemas a la vez que, por sus propias características, genera otros. Pero no es este el lugar adecuado para desarrollas estas tesis que, por otro lado, son verdaderamente interesantes.

\subsection{Instrumentos internacionales más relevantes en materia de acceso a la información ambiental}

Debemos empezar, sin duda alguna, por la Conferencia Mundial de Estocolmo del año 1972, o Conferencia de naciones Unidas sobre el Medio Humano. Bien es cierto que en esta Conferencia no se hace referencia expresamente al derecho de acceso a la información ambiental, pero lo relevante es que, por primera vez en la historia de la humanidad, se toma conciencia internacional sobre los problemas que genera la degradación del medio ambiente. No obstante, en la Declaración de 26 principios que surge de esta Cumbre, podemos alcanzar a ver el embrión de lo que más adelante será el derecho que se trata en el presente trabajo. ${ }^{14}$

2 LATORRE, A. Introducción al Derecho. Madrid: Ariel, 2008.

13 SCHMIDT-ASSMAN, E. "La ciencia del Derecho Administrativo ante la internacionalización de las relaciones administrativas", Revista de Administración Pública, Madrid, n. 171, pág. 9, 2006.

14 Así, el principio 19 de la citada Declaración señala que: "Es indispensable una labor de educación en cuestiones ambientales, dirigida tanto a las generaciones jóvenes como a los adultos y que presente la debida atención al sector de población menos privilegiado, para ensanchar las bases de una opinión pública bien informada y de una conducta de los individuos, de las empresas y de las colectividades inspirada en el sentido de su responsabilidad en cuanto a la protección y mejoramiento del medio en toda su dimensión humana. Es también esencial que los medios de comunicación de masas eviten contribuir al deterioro del medio humano y difundan, por el contrario, información de carácter educativo sobre la necesidad de protegerlo y mejorarlo, a fin de que el hombre pueda desarrollarse en todos los aspectos". Por su parte, el principio 20 señala que: "Se deben fomentar en todos los países en desarrollo, la investigación y el desarrollo científicos referentes a los problemas ambientales, tanto nacionales como multinacionales. A este respecto, el libre intercambio de información científica actualizada y de experiencias sobre la transferencia de ser objeto de apoyo y asistencia, a fin de facilitar la solución de los problemas ambientales; las tecnologías ambientales deben ponerse a disposición de los países en desarrollo en condiciones que favorezcan su amplia difusión sin que constituyan una carga económica excesiva para esos países". 
Pero es en la Declaración de Rio, surgida en la Conferencia de Rio de Janeiro sobre el medio ambiente y el desarrollo celebrada en esta ciudad brasileña del 3 al 14 de junio de 1992, ${ }^{15}$ cuando se hace referencia, por primera vez, al derecho de acceso a la información ambiental como un principio necesario para lograr una adecuada protección del medio ambiente. Por su importancia, reproduzco aquí el principio 10 de la citada Declaración:

El mejor modo de tratar las cuestiones ambientales es con la participación de todos los ciudadanos interesados, en el nivel que corresponda. En el plano nacional, toda persona deberá tener acceso adecuado a la información sobre el medio ambiente de que dispongan las autoridades públicas, incluida la información sobre los materiales y las actividades que encierran peligro en sus comunidades, así como la oportunidad de participar en los procesos de adopción de decisiones. Los Estados deberán facilitar y fomentar la sensibilización y la participación de la población poniendo la información a disposición de todos. Deberá proporcionarse acceso efectivo a los procedimientos judiciales y administrativos, entre, éstos el resarcimiento de daños y los recursos pertinentes.

Como se puede observar, ya en la Declaración de Rio de 1992 se hace referencia al derecho de acceso a la información ambiental, que ha de reconocerse a toda persona sin necesidad de acreditar un interés legítimo determinado (amplia legitimidad), haciendo especial hincapié en aquella información sobre actividades que puedan suponer un riesgo para las comunidades (derecho a la vida y a la integridad física), así como en la participación de todos los ciudadanos en la toma de decisiones sobre la materia, y para la que resulta imprescindible haber facilitado, con carácter previo, toda la información disponible.

Pero el verdadero referente internacional en materia de acceso a la información en materia ambiental lo encontramos en el Convenio de Aarhus de 25 de junio de 1998, sobre acceso a la información, participación pública en la toma de decisiones y acceso a la justicia en temas medioambientales. Este Convenio,

15 Esta Conferencia mundial sobre el Medio Ambiente y el Desarrollo tiene su origen en un importante documento denominado "Informe Brundtland" (inicialmente se llamó “Nuestro Fututo Común") elaborado en 1987 en el seno de la Organización de Naciones Unidas por un grupo de expertos encabezado por la que fuera primera ministra de Noruega Leo Harlem Bruntland. En este documento se habla, por primera vez, del desarrollo sostenible como principio esencial para la protección del medio ambiente, de tal forma que en el desarrollo económico y el uso de los recursos debe realizarse de tal forma que se satisfagan las necesidades del presente sin comprometer las necesidades de las futuras generaciones. Para una visión más pormenorizada de este principio véase PIÑAR MAÑAS, J. L. (Coord.) Desarrollo sostenible y protección del medio ambiente. Madrid: Civitas, 2002. 
adoptado por la Comisión Económica de Naciones Unidas para Europa, fue ratificado por la entonces Comunidad Europea (una de las organizaciones internacionales que formaban la Unión Europea). En este instrumento se pone de manifiesto la indisoluble unión entre el derecho de acceso a la información ambiental, reconocido como derecho autónomo y no instrumental, y el desarrollo sostenible y el derecho a la vida y a la integridad física. Así, en el artículo 1, refiriéndose al objetivo del Convenio, se señala expresamente que:

A fin de contribuir a proteger el derecho de cada persona, de las generaciones presentes y futuras, a vivir en un medio ambiente que permita garantizar su salud y su bienestar, cada Parte garantizará los derechos de acceso a la información sobre el medio ambiente, la participación del público en la toma de decisiones y el acceso a la justicia en materia medioambiental de conformidad con las disposiciones del presente Convenio.

En definitiva, resulta imprescindible el reconocimiento del derecho de acceso a la información ambiental y la participación en esta materia para garantizar una adecuada protección del medio ambiente así como el derecho a la vida con unas mínimas condiciones de calidad. Sin aquellos, difícilmente podrá alcanzarse esta. Por ello, no nos puede resultar difícil poner en relación indisoluble el derecho de acceso a la información ambiental con el derecho a la participación reconocido en el artículo 23 de la Constitución o, incluso, el derecho a la vida del artículo 15 de nuestra Norma Fundamental. En esto consiste la "ecologización" de los derechos fundamentales o la dimensión ambiental de los derechos fundamentales a la que me he referido más arriba, de manera que una vulneración del derecho de acceso a la información ambiental pudiera verse como un atentado contra el derecho fundamental a la participación o el derecho a la vida o la integridad física y moral. Esta es una de las tesis que defiendo en este trabajo.

Y es que el Convenio de Aarhus se basa en tres pilares fundamentales:

- Acceso a la información ambiental

- Participación de los ciudadanos en materia ambiental

- Acceso a la justicia en materia ambiental

Independientemente del reconocimiento autónomo de cada uno de estos derechos, debemos tener en cuenta que tienen un orden lógico sucesivo, pues sin el reconocimiento de un verdadero derecho de acceso, difícilmente se podrá participar con conocimiento de causa o ejercer las acciones judiciales correspondientes. De ahí que la base de todo este entramado sea el derecho de acceso a la información. ${ }^{16}$

16 LOZANDO CUTANDA, B. Derecho Ambiental Administrativo, cit., pág. 232, “El derecho de acceso a la información ambiental, además de desempeñar un papel esencial en la concienciación y educación 


\section{El reconocimiento del derecho de acceso a la información ambiental en el derecho de la Unión Europea}

Ya hemos indicado que la Unión Europea (a través de la entonces Comunidad Europea) ratificó el Convenio de Aarhus y, por tanto, debía hacer efectivos los derechos allí contenidos en su propio ordenamiento. Para ello se aprobaron dos normas esenciales (que refiero por orden de importancia, no cronológico): ${ }^{17}$

- Reglamento (CE) 1367/2006 del Parlamento Europeo y del Consejo, de 6 de septiembre de 2006, relativo a la aplicación del Convenio a las instituciones y a los organismos comunitarios. Se utilizó este tipo de norma, con eficacia directa e inmediata, para regular el derecho de acceso a la información ambiental que obre en poder de las instituciones y organismos de la Unión Europea en el ejercicio de sus propias competencias en la materia. Esta norma ha adquirido especial importancia desde la aprobación del Tratado de Funcionamiento de la Unión Europea que, como es sabido, amplía las competencias de la Unión en materia medioambiental. ${ }^{18}$ Este Reglamento viene a completar el derecho de acceso en general reconocido en el Reglamento (CE) ㄲo 1049/2001 del Parlamento Europeo y del Consejo, de 30 de mayo de 2001, relativo al acceso del público a los documentos del Parlamento Europeo, del Consejo y de la Comisión.

- Directiva 2003/4/CE del Parlamento Europeo y del Consejo, de 28 de enero de 2003, relativa al acceso del público a la información medioambiental. A través de esta norma, que debía ser transpuesta por los diferentes Estados miembros a su ordenamiento, se regula el derecho de acceso a la información ambiental que obre en poder de los diferentes Estados en el ejercicio de sus propias competencias en materia ambiental.

- Directiva 2003/35/CE del Parlamento Europeo y del Consejo, de 26 de mayo de 2003, por la que se establecen medidas para la participación del público en la elaboración de determinados planes y programas

ambiental de la sociedad, constituye un instrumento indispensable para hacer efectivos los otros dos pilares del Convenio de Aarhus, pues si los ciudadanos no disponen de una información ambiental relevante en cada momento difícilmente podrán intervenir de forma efectiva, con conocimiento de causa, en los asuntos públicos que atañen a este bien jurídico colectivo.

17 No obstante, es necesario indicar que antes del Convenio de Aarhus existía la Directiva 90/313/CEE del Consejo, de 7 de junio de 1990, sobre libertad de acceso a la información en materia de medio ambiente, que se desarrolló en nuestro país por medio de la Ley 38/1995, de 12 de diciembre, sobre el derecho de acceso a la Información en materia de Medio Ambiente.

18 El artículo 3 del Tratado de Funcionamiento otorga competencias exclusivas a la Unión sobre "la conservación de los recursos biológicos marinos dentro de la política pesquera común; El artículo 4, por su parte, señala que el medio ambiente es una competencia compartida con los Estados miembros. 
relacionados con el medio ambiente y por la que se modifican, en lo que se refiere a la participación del público y el acceso a la justicia, las Directivas 85/337/CEE y 96/61/CE del Consejo.

Por otro lado, cabe señalar que el derecho de acceso está regulado, con carácter general, en la Carta de Derechos Fundamentales de la Unión Europea, en cuyo artículo 42 (dentro del Capítulo V, relativo a los derechos de ciudadanía) se indica que "Todo ciudadano de la Unión o toda persona física o jurídica que resida o tenga su domicilio social en un Estado miembro tiene derecho a acceder a los documentos del Parlamento Europeo, del Consejo y de la Comisión". Este derecho se refiere al acceso a los documentos, no a la información que es lo verdaderamente relevante. En cualquier caso, repito, se refiere a los documentos en general, no específicamente a aquellos que contengan información ambiental, aunque, como es lógico, también se aplica a aquellos supuestos en el que los ciudadanos $u$ otras personas jurídicas soliciten el acceso a documentos relacionados con el medio ambiente.

El derecho de acceso a la información en general, tanto a la relacionada con el medio ambiente como a cualquier otra, es especialmente importante para la Unión Europea habida cuenta de la preocupación de las instituciones comunitarias por abrirse a los ciudadanos, o en otras palabras, por la Gobernanza. ${ }^{19}$ Así, en el Libro Blanco para la Gobernanza Europea ${ }^{20}$ se pone de manifiesto que "Es necesario reformar la gobernanza europea para acercar a los ciudadanos las instituciones europeas. Una buena gobernanza se basa en cinco principios acumulativos:

- Apertura

- Participación

- Responsabilidad

- Eficacia

- Coherencia

Así siguiendo esta política de apertura, también se ha aprobado el Reglamento (CE) no 1049/2001 del Parlamento Europeo y del Consejo, de 30 de mayo de 2001, relativo al acceso del público a los documentos del Parlamento Europeo, del Consejo y de la Comisión. Esta norma regula el acceso a cualquier documento, tenga o no carácter ambiental. Sin embargo, para el acceso a la documentación ambiental, habrá de tenerse en cuenta el Reglamento (CE) 1367/2006 del

19 La preocupación por la apertura en el ámbito de la Unión Europea viene motivado, fundamentalmente, por el denominado déficit democrático, es decir, la falta de legitimidad democrática de sus instituciones. De ahí que para intentar paliar de algún modo este déficit se pretenda dotar de mayor transparencia a la Unión y fomentar la participación de los ciudadanos a través de diversos instrumentos de iniciativa ciudadana.

20 Comunicación de la Comisión, de 25 de julio de 2001, "La gobernanza europea - Un Libro Blanco" [COM (2001) 428 final - Diario Oficial C 287 de 12.10.2001]. 
Parlamento Europeo y del Consejo, de 6 de septiembre de 2006, que es mucho más completo, pues regula no solo el derecho de acceso, sino también la recogida y difusión de información ambiental por parte de los organismos e instituciones europeas, es decir, lo que en los últimos tiempos ha venido en llamarse la transparencia activa. Además, por supuesto, de la participación y del acceso a la justicia en materia medioambiental, con el recurso, en su caso, ante el Tribunal de Justicia.

Sin embargo, ambos instrumentos no entran en conflicto, sino que complementarios. De hecho, el artículo 3 del Reglamento no 1367/2006, sobre información ambiental, remite expresamente al Reglamento no 1049/2001, que regula el acceso general a los documentos. Esto implica que cualquier solicitud de acceso, sea o no a un documento relacionado con materia medioambiental, se tramita siguiendo el procedimiento previsto en este. Si la solicitud se refiere a un documento donde se contiene información ambiental, se aplicará, con carácter adicional, lo previsto en el Reglamento no 1367/2006, que como ya se ha indicado, es mucho más completo.

En España, sin embargo, la opción elegida difiere de la que acabamos de mencionar. Mientras en la Unión Europea existen, como hemos visto, dos Reglamentos, uno general y otro sectorial, que se complementan. En nuestro ordenamiento se ha optado por dos leyes, una sectorial que se aplica con carácter prioritario, y otra general, más reciente, que solo se aplicara subsidiariamente para todo aquello que no regule aquella.

\section{Marco constitucional del derecho de acceso a la información ambiental}

El derecho de acceso a la información en general, sea ambiental o no, viene reconocido en el artículo 105.c) de nuestra Norma Fundamental. ${ }^{21}$ Así, se considera más un principio de actuación administrativa ${ }^{22}$ que un verdadero derecho fundamental. Por ello, la ley 27/2006, de 18 de julio, que lo desarrolla, no tiene carácter orgánico, sino ordinario.

21 La Ley regulará:

[...]

b) El acceso de los ciudadanos a los archivos y registros administrativos, salvo en lo que afecte a la seguridad y defensa del Estado, la averiguación de los delitos y la intimidad de las personas.

22 PIÑAR MAÑAS en "Seguridad, transparencia y protección de datos: el futuro de un necesario equilibrio", cit., pág. 33. 
Por su parte, el artículo 45 de nuestra Constitución, ${ }^{23}$ que recoge el derecho a la protección del medio ambiente, no se refiere de manera expresa al derecho de acceso a la información ambiental. Sin embargo, se puede entender reconocido implícitamente, pues no es posible ejercer el derecho a disfrutar del medio ambiente, así como cumplir la obligación de conservarlo, sin una información adecuada.

No obstante, la ubicación de este artículo impide que, a priori, pueda ser considerado como un derecho fundamental susceptible de amparo constitucional. Se encuentra situado, como es sabido, entre los principios rectores de la política social y económica, lo que, en virtud del artículo 53.3, de la propia Constitución, requiere de una previa Ley que lo desarrolle para poder ejercerlos ante los tribunales.

Sin embargo, como ya hemos indicado más arriba, en los últimos años hemos asistido a una "ecologización" de los derechos fundamentales, como consecuencia sobre todo de la jurisprudencia del Tribunal Europeo de Derechos Humanos. Esta "ecologización" o dimensión ambiental de los derechos fundamentales consiste en considerar que ciertos daños cometidos sobre medio ambiente pueden dañar otros derechos como el derecho a la vida y a la salud, así como a la integridad física y moral, sin olvidar que el medio ambiente es un elemento esencial para el desarrollo de la persona, y por tanto para su dignidad. De ahí que los daños ambientales de estos derechos fundamentales abran la posibilidad de, una vez agotada la vía judicial correspondiente, acudir al recurso de amparo ante el Tribunal Constitucional. ${ }^{24}$

Y en virtud de esta dimensión ambiental de los derechos fundamentales, considero que el propio derecho de acceso a la información en la materia puede ser interpretado desde esta misma perspectiva. Es decir, el derecho de acceso a la información medioambiental, como integrado en el derecho más amplio a la protección del medio ambiente, puede ser considerado un derecho fundamental

23 Artículo 45.

1. Todos tienen el derecho a disfrutar de un medio ambiente adecuado para el desarrollo de la persona, así como el deber de conservarlo.

2. Los poderes públicos velarán por la utilización racional de todos los recursos naturales, con el fin de proteger y mejorar la calidad de la vida y defender y restaurar el medio ambiente, apoyándose en la indispensable solidaridad colectiva.

3. Para quienes violen lo dispuesto en el apartado anterior, en los términos que la ley fije se establecerán sanciones penales o, en su caso, administrativas, así como la obligación de reparar el daño causado.

24 Así lo ha manifestado LOZANO CUTANDA, B., Derecho Ambiental Administrativo, cit., pág. 81. 


\section{El derecho de acceso a la información ambiental a la vista de la aprobación de la nueva Ley de Transparencia. Análisis comparativo de ambas regulaciones}

En España no ha habido tradición sobre transparencia. Más bien al contrario, nos hemos caracterizado por una opacidad que nos situaba entre los países peor situados del ranking internacional sobre la transparencia y el acceso a la información. Esa ausencia de transparencia no facilitaba, en modo alguno, el ejercicio, en sana democracia, ${ }^{25}$ del derecho a la participación ciudadana o el derecho a recibir información por cualquier medio de comunicación. Muy al contrario, aumentaba la sensación de corrupción y secretismo que en una situación de crisis económica, política y social como la que estamos viviendo, incrementa la brecha que separa el Estado de la sociedad civil. ${ }^{26}$

Sin embargo, en la actualidad la cosa parece estar cambiando. Y no precisamente por la aprobación de la reciente Ley 19/2013, de 9 de diciembre, sobre transparencia, acceso a la información y buen gobierno, pues como ha señalado el profesor José Luis Piñar Mañas, ahora somos un país con Ley de transparencia pero sin transparencia. Digo que la percepción está cambiando porque son cada vez más las voces en España que reclaman una verdadera transparencia y el reconocimiento del derecho de acceso a la información como un verdadero derecho fundamental de los de más alto rango, es decir, de los que, según el ordenamiento constitucional español serían susceptibles de recurso de amparo ante el Tribunal Constitucional. ${ }^{27}$ En este sentido, parece que nos

25 Como muy acertadamente indica el profesor José Luis PIÑAR MAÑAS, en "Seguridad, transparencia y protección de datos: el futuro de un necesario equilibrio", Documento de Trabajo 147/2009, Fundación Alternativas, 2009, pág. 31, “La transparencia es esencial en las sociedades democráticas. no sólo en relación con el sector público, sino como principio configurador de la sociedad"

26 Sobre esta separación, cada vez más acusada, véase la interesante obra de ESTEVE PARDO, J., La nueva relación entre Estado y Sociedad. Aproximación al trasfondo de la crisis. Madrid: Marcial Pons, 2013.

27 Véase en este sentido lo manifestado por el profesor José Luis Piñar Mañas en "Seguridad, transparencia y protección de datos: el futuro de un necesario equilibrio", cit., pág. 33, "Ahora bien, el acceso a la información, ¿es un derecho o un principio de actuación de las Administraciones públicas? La respuesta que se dé es de suma importancia en las relaciones entre protección de datos y transparencia, pues si aquélla es un derecho fundamental y ésta un simple principio de actuación, es evidente que la primera debe siempre prevalecer sobre la segunda. $\mathrm{Si}$, por el contrario, consideramos que se trata de un derecho fundamental, el equilibrio debe buscarse desde otros parámetros muy diferentes.

En el Derecho español parece que prevalece la configuración de la transparencia como principio de actuación de las Administraciones públicas. Así se desprendería de la propia ubicación del artículo 105.b) de la Constitución, incluido en el Título IV, sobre el Gobierno y la Administración. El artículo 3.5 de la Ley 30/1992 dispone que "en sus relaciones con los ciudadanos las Administraciones públicas actúan de conformidad con los principios de transparencia y participación”. El Preámbulo de la Ley 4/2006, de 30 de junio, de transparencia y de buenas prácticas en la Administración pública gallega, afirma que al regular la transparencia se contribuye a "hacer más efectivo el derecho a una buena Administración, como principio consagrado en nuestro acervo jurídico desde la aprobación de la Carta de los derechos fundamentales de 
encontramos en un momento de plena transición hacia la consideración del derecho de acceso como un derecho fundamental. Así parece deducirse de la mas reciente jurisprudencia del Tribunal Europeo de Derechos Humanos. En concreto, las sentencias de 26 de mayo, Kenedi c. Hungría y de 25 de junio de 2013, Youth Initiative for Human Rights $c$. Serbia donde se engarza el derecho de acceso a la información con el artículo 10 del Convenio Europeo de Derechos Humanos relativo a la libertad para transmitir y recibir información. ${ }^{28}$

Esta conversión del derecho de acceso a la información en un verdadero derecho fundamental de los de más alto rango constitucional me parece más fácil, sin embargo, cuando se trata de información ambiental. A ello ya me he referido más arriba. $Y$ es que cuando hablamos del derecho a la información ambiental, además de acudir al anclaje del derecho a la información del artículo 20 y del derecho a la participación del artículo 23, que no es poco, podemos acudir a otros derechos como el de la dignidad (artículo 10) o el derecho a la vida y a la integridad física y moral (artículo 15). ${ }^{29}$ Teniendo en cuenta, además, que según la jurisprudencia del Tribunal Europeo de Derechos Humanos, los derechos fundamentales han de observarse desde una perspectiva ambiental que permita esta interpretación.

Es por ello que estimo que en nuestro país se alcanzará este objetivo por la vía ambiental. Es decir, primero se reconocerá el derecho a la información ambiental como un derecho fundamental, de acuerdo con la interpretación ecológica de los derechos fundamentales, para después ampliar posteriormente esta característica al resto de la información.

Ia Unión Europea”. También la profesora Leonor RAMS RAMOS, “La transformación del derecho de acceso en España: de derecho de configuración legal a derecho fundamental", Revista Española de Derecho Administrativo, núm. 160, 2013, defiende la consideración del derecho de acceso a la información como un auténtico derecho fundamental anclado en el artículo 20 de nuestra Norma Fundamental

28 RAMS RAMOS, L. "La transformación del derecho de acceso en España: de derecho de configuración legal a derecho fundamental", cit.

29 No obstante, el Tribunal Supremo no parece muy proclive a dicha interpretación a la vista de lo establecido en la Sentencia del 14 de febrero de 2011 (sección 7a), de la Sala Tercera, donde se indica en el Fundamento Jurídico Quinto, en relación con el derecho de acceso a la información ambiental que:

“En efecto, como bien dice el Ministerio Fiscal, no estamos ante un supuesto en el que se hayan desconocido los derechos fundamentales a la libre expresión del pensamiento ni a comunicar y recibir información veraz por cualquier medio. De lo que se trata es del acceso a la documentación que obra en un expediente administrativo cuya tramitación está prevista en unas normas especiales. Expediente que no tiene tampoco que ver con la participación en los asuntos públicos a que se refiere el artículo 23.1 de la Constitución. Estamos, por el contrario, en el ámbito de su artículo 105 y de la legislación que lo ha desarrollado y de su aplicación en lo que se refiere a la procedencia de incluir o no en el LVTL una nueva tecnología". 


\subsection{Aplicación preferente de la Ley $27 / 2006$, de 18 de julio frente a la Ley 19/2013, de 9 de diciembre. Definición de información medioambiental}

Como consecuencia de la ratificación del Convenio de Aarhus, y de la aprobación de las Directivas 2003/4/CE del Parlamento Europeo y del Consejo, de 28 de enero de 2003, relativa al acceso del público a la información medioambiental, y 2003/35/CE del Parlamento Europeo y del Consejo, de 26 de mayo de 2003, por la que se establecen medidas para la participación del público en la elaboración de determinados planes y programas relacionados con el medio ambiente y por la que se modifican, en lo que se refiere a la participación del público y el acceso a la justicia, las Directivas 85/337/CEE y 96/61/CE del Consejo, y para llevar a cabo su transposición, se aprueba en nuestro país la Ley $27 / 2006$, de 18 de julio, por la que se regulan los derechos de acceso a la información, de participación pública y de acceso a la justicia en materia de medio ambiente. ${ }^{30}$

Al margen de la regulación prevista en el artículo 37 de la Ley 30/1992, de 26 de noviembre, de Régimen Jurídico de las Administraciones Públicas y del Procedimiento Administrativo Común, que se había quedado a todas luces obsoleta y era manifiestamente insuficiente, la regulación contenida en la Ley 27/2006 era la única prevista sobre transparencia en nuestro país, aunque estuviera restringida a materia medioambiental. Al menos así era hasta la aprobación de la reciente Ley 19/2013, de 9 de diciembre, sobre transparencia, acceso a la información y buen gobierno.

Sin embargo, después de la aprobación de esta Ley, que tiene carácter general, en materia medioambiental se sigue aplicando, con carácter preferente, la ley 27/2006. Y ello en virtud de la Disposición Adicional Primera, apartado 2, de la Ley 19/2013, de 9 de diciembre, que establece expresamente que "Se regirán por su normativa específica, y por esta Ley con carácter supletorio, aquellas materias que tengan previsto un régimen jurídico específico de acceso a la información", es decir, el acceso a la información medioambiental. De manera que la nueva Ley de transparencia solo se aplicará con carácter supletorio en materia de acceso a la información ambiental, a la que se aplica, con carácter preferente, su legislación sectorial.

30 Esta Ley vino a derogar, como ya se ha indicado, la Ley 38/1995, de 12 de diciembre, sobre el derecho de acceso a la Información en materia de Medio Ambiente, que incorporaba en nuestro ordenamiento la también derogada Directiva 90/313/CEE del Consejo, de 7 de junio de 1990, sobre libertad de acceso a la información en materia de medio ambiente. 
Lo relevante, por consiguiente, a la vista de lo anterior, será determinar lo que ha de considerarse información ambiental, ${ }^{31}$ pues eso determinará la aplicación de una Ley u otra. En este sentido, la Ley 27/2006, de 18 de julio, da una definición muy amplia de información ambiental, incluyendo cuestiones que, en sentido estricto, no han de considerarse, a priori, como ambientales. Así, el artículo 2.3 de la Ley define información ambiental como:

3. Información ambiental: toda información en forma escrita, visual, sonora, electrónica o en cualquier otra forma que verse sobre las siguientes cuestiones:

a) El estado de los elementos del medio ambiente, como el aire y la atmósfera, el agua, el suelo, la tierra, los paisajes y espacios naturales, incluidos los humedales y las zonas marinas y costeras, la diversidad biológica y sus componentes, incluidos los organismos modificados genéticamente; y la interacción entre estos elementos.

b) Los factores, tales como sustancias, energía, ruido, radiaciones o residuos, incluidos los residuos radiactivos, emisiones, vertidos y otras liberaciones en el medio ambiente, que afecten o puedan afectar a los elementos del medio ambiente citados en la letra a).

c) Las medidas, incluidas las medidas administrativas, como políticas, normas, planes, programas, acuerdos en materia de medio ambiente y actividades que afecten o puedan afectar a los elementos y factores citados en las letras a) y b), así como las actividades o las medidas destinadas a proteger estos elementos.

d) Los informes sobre la ejecución de la legislación medioambiental.

e) Los análisis de la relación coste-beneficio y otros análisis y supuestos de carácter económico utilizados en la toma de decisiones relativas a las medidas y actividades citadas en la letra c), y

f) El estado de la salud y seguridad de las personas, incluida, en su caso, la contaminación de la cadena alimentaria, condiciones de vida humana, bienes del patrimonio histórico, cultural y artístico y construcciones, cuando se vean o puedan verse afectados por el estado de los elementos del medio ambiente citados en la letra a) o, a través de esos elementos, por cualquiera de los extremos citados en las letras b) y c).

31 FERNÁNDEZ VALVERDE, R., "La integración de las exigencias del Convenio de Aarhus en el sistema procesal español a través de la Ley $27 / 2006$ ", cit., pág. 86. 
Cabe indicar, por consiguiente, que el término "información ambiental" ha de interpretarse de forma amplia, pues están incluidas informaciones relacionadas con el patrimonio histórico, cultural y artístico, etcétera, que no son propiamente información ambiental. ${ }^{32}$

\subsection{La regulación de la transparencia activa. Control por parte del Consejo de la Transparencia y Buen Gobierno}

Ambas leyes, tanto la general como la sectorial regulan la llamada transparencia activa, entendiendo esta como aquella que tiene que difundir la propia administración o entidad pública correspondiente sin que medie una solicitud.

En la Ley $27 / 2006$, de 18 de julio, la publicidad activa está regulada en los artículos 6 a 9, ${ }^{33}$ incluyendo una regulación muy detallada de lo que debe publicarse. Así, sin ánimo de ser exhaustivos, se incluyen: normas y resoluciones judiciales; políticas; programas; informes; datos; autorizaciones; evaluaciones de impacto ambiental; informes sobre el estado del medio ambiente, información sobre amenazas inminentes.

Sin embargo, la Ley 19/2013 (artículos 5 a 11), es mucho más difusa en cuanto a la información que debe ser objeto de publicidad activa. Se utilizan términos más genéricos como instrucciones, directrices, acuerdos, etcétera. Aunque también se refiere a anteproyectos de ley, reglamentos y otras normas.

No obstante, Ia diferencia esencial radica en que mientras la Ley 19/2013, de 9 de diciembre, prevé que el cumplimiento de esta obligación de publicidad activa ha de ser controlado por el Consejo de Transparencia y Bueno Gobierno según lo establecido en el artículo 9, pudiendo llegar a la imposición de sanciones, llegado el caso, la Ley $27 / 2006$, de 18 de julio, no prevé ningún tipo de control sobre el cumplimiento de las obligaciones de difusión activa. No obstante, siendo aquella Ley de aplicación supletoria para todo aquello que no esté específicamente regulada en esta, cabe interpretar que desde que se constituya el Consejo de Transparencia y Buen Gobierno este habrá de ocuparse, igualmente, del cumplimiento de la obligación de publicación de la información ambiental conforme a lo previsto en la Ley sectorial.

32 Así lo han puesto de manifiesto el Tribunal de Justicia de la Unión Europea (sentencias de 17 de junio de 1998 y 12 de junio de 2000) o el Tribunal Superior de Justicia del País Vasco Sala de lo Contencioso Administrativo (sentencia de 16 de junio de 2003).

33 FERNÁNDEZ VALVERDE, R., "La integración de las exigencias del Convenio de Aarhus en el sistema procesal español a través de la Ley 27/2006", cit., pág. 92. 


\subsection{El titular del derecho de acceso a la información y el sujeto obligado a suministrarla}

En relación al reconocimiento del derecho de acceso a la información ambiental, da la impresión de que la Ley $27 / 2006$, de 18 de julio, establece una legitimidad activa más amplia que la reconocida en la Ley 19/2013, de 9 de diciembre.

Así, poniendo en relación los artículos 2.7 y 10 de la Ley sectorial, se establece que podrá solicitar la información ambiental: "Cualquier persona física y jurídica, así como asociaciones, organizaciones o grupos”. Se incluyen, como vemos, asociaciones, organizaciones o grupos sin necesidad de que acrediten personalidad jurídica.

El artículo 12 de la Ley 19/2013, de 9 de diciembre, sin embargo, establece que "Todas las personas tienen derecho a acceder a la información pública". Ante esta afirmación, cabe preguntarse, ¿solo las personas, o también las asociaciones, organizaciones o grupos aunque no se hayan constituido como personas jurídicas, tal y como establece la Ley sectorial? La precisión no es baladí, pues si se hace una interpretación restrictiva de este artículo, podría impedirse el ejercicio del derecho de acceso a determinados grupos que sin haberse constituido como personas jurídicas, pretenden solicitar determinada información. No obstante, la entidad ante la que se ejercita este derecho de acceso debiera interpretar el artículo lo más ampliamente posible, sin exigir que el solicitante este constituido como persona jurídica.

Por otro lado, ambas leyes tienen en común que ninguna exige la acreditación de interés legítimo alguno para el ejercicio del derecho de acceso.

En cuanto al sujeto obligado a suministrar la correspondiente información, ambas leyes coinciden en señalar que será aquel en cuyo poder se encuentre la misma. Así lo señala el artículo 10 de la Ley 27/2006 y el artículo 17 de la Ley 19/2013. Sin embargo, mientras que la Ley sectorial impone a las autoridades correspondientes la obligación de asistencia a los ciudadanos que hayan presentado una solicitud imprecisa, la Ley general nada dice al respecto, pese a que esta obligación pueda derivarse de Ley general de procedimiento administrativo (Ley 30/1992, de 26 de noviembre), de acuerdo con lo establecido en su artículo 35.

\subsection{Causas de denegación del derecho de acceso a la información. Especial referencia la protección de datos}

Voy a referirme a continuación a la regulación de los motivos por los cuales se puede denegar el derecho de acceso a la información. Las dos regulaciones 
señalan prácticamente las mismas causas de denegación, aunque con algunos matices que deben indicarse. ${ }^{34}$

Como rasgos en común, se debe señalar que las causas de denegación han de interpretarse de manera restrictiva y, en cualquier caso, se deberá realizar una ponderación adecuada entre los intereses en juego. Si no fuese posible suministrar todo la información que se solicita, deberá permitirse, al menos, un acceso parcial. Así lo prevén ambas leyes, la general y la sectorial.

Por su parte, la Ley $26 / 2007$, de 18 de julio, distingue entre causas formales y causas materiales de denegación (apartados 1 y 2 del artículo 13), ${ }^{35}$ mientras

34 Sobre la causas de denegación del derecho de acceso a la información ambiental, véase CUBERO MARCOS, J. I. "Excepciones al derecho de acceso a la información ambiental”, en LOZANO CUTANDA, B.; GUTIERREZ-ALVIZ CONRADI, F. (Dirs.). Examen de la nueva ley de acceso a la información, participación pública y acceso a la justicia en materia de medio ambiente, cit., págs. 141 a 166.

35 Artículo 13 Excepciones a la obligación de facilitar la información ambiental

1. Las autoridades públicas podrán denegar las solicitudes de información ambiental cuando concurra cualquiera de las circunstancias que se indican a continuación:

a) Que la información solicitada a la autoridad pública no obre en poder de ésta o en el de otra entidad en su nombre, sin perjuicio de lo dispuesto en el artículo 10.2.b).

b) Que la solicitud sea manifiestamente irrazonable.

c) Que la solicitud esté formulada de manera excesivamente general, teniendo en cuenta lo dispuesto en el artículo 10.2.a).

d) Que la solicitud se refiera a material en curso de elaboración o a documentos o datos inconclusos. Por estos últimos se entenderán aquellos sobre los que la autoridad pública esté trabajando activamente. Si la denegación se basa en este motivo, la autoridad pública competente deberá mencionar en la denegación la autoridad que está preparando el material e informar al solicitante acerca del tiempo previsto para terminar su elaboración.

e) Que la solicitud se refiera a comunicaciones internas, teniendo en cuenta el interés público atendido por la revelación.

2. Las solicitudes de información ambiental podrán denegarse si la revelación de la información solicitada puede afectar negativamente a cualquiera de los extremos que se enumeran a continuación:

a) A la confidencialidad de los procedimientos de las autoridades públicas, cuando tal confidencialidad esté prevista en una norma con rango de Ley.

b) A las relaciones internacionales, a la defensa nacional o a la seguridad pública.

c) A causas o asuntos sujetos a procedimiento judicial o en trámite ante los tribunales, al derecho de tutela judicial efectiva o a la capacidad para realizar una investigación de índole penal o disciplinaria. Cuando la causa o asunto estén sujetos a procedimiento judicial o en trámite ante los tribunales, deberá, en todo caso, identificarse el órgano judicial ante el que se tramita.

d) A la confidencialidad de datos de carácter comercial e industrial, cuando dicha confidencialidad esté prevista en una norma con rango de Ley o en la normativa comunitaria, a fin de proteger intereses económicos legítimos, incluido el interés público de mantener la confidencialidad estadística y el secreto fiscal.

e) A los derechos de propiedad intelectual e industrial. Se exceptúan los supuestos en los que el titular haya consentido en su divulgación.

f) Al carácter confidencial de los datos personales, tal y como se regulan en la Ley Orgánica 15/1999, de 13 de diciembre, de Protección de Datos de Carácter Personal, siempre y cuando la persona interesada a quien conciernan no haya consentido en su tratamiento o revelación.

g) A los intereses o a la protección de un tercero que haya facilitado voluntariamente la información solicitada sin estar obligado a ello por la legislación vigente. Se exceptúan los supuestos en los que la persona hubiese consentido su divulgación.

h) A la protección del medio ambiente al que se refiere la información solicitada. En particular, la que se refiera a la localización de las especies amenazadas o a la de sus lugares de reproducción. 
que la Ley 19/2013, de 9 de diciembre, distingue entre límites del derecho de acceso (artículo 14) ${ }^{36}$ y causas de inadmisión (artículo 18). ${ }^{37}$ Pero como ya hemos indicado más arriba coinciden las causas en ambas regulaciones.

Sí se aprecia alguna diferencia de relieve en cuanto al tratamiento de la protección de datos como causa de denegación del derecho de acceso. Mientras en la ley $27 / 2006$, de 18 de julio, simplemente se refiere la protección de datos personales como causa de denegación del derecho de acceso a la información ambiental, la Ley 19/2013, de 9 de diciembre, realiza una regulación muy detallada, impidiendo que la protección de datos sea utilizada de manera instrumental para impedir, con carácter general, el cumplimiento de la obligación de transparencia y el derecho de acceso. ${ }^{38}$

36 Artículo 14 Límites al derecho de acceso

1. El derecho de acceso podrá ser limitado cuando acceder a la información suponga un perjuicio para:

a) La seguridad nacional.

b) La defensa.

c) Las relaciones exteriores.

d) La seguridad pública.

e) La prevención, investigación y sanción de los ilícitos penales, administrativos o disciplinarios.

f) La igualdad de las partes en los procesos judiciales y la tutela judicial efectiva.

g) Las funciones administrativas de vigilancia, inspección y control.

h) Los intereses económicos y comerciales.

i) La política económica y monetaria.

j) El secreto profesional y la propiedad intelectual e industrial.

k) La garantía de la confidencialidad o el secreto requerido en procesos de toma de decisión.

I) La protección del medio ambiente.

37 Artículo 18 Causas de inadmisión

1. Se inadmitirán a trámite, mediante resolución motivada, las solicitudes:

a) Que se refieran a información que esté en curso de elaboración o de publicación general.

b) Referidas a información que tenga carácter auxiliar o de apoyo como la contenida en notas, borradores, opiniones, resúmenes, comunicaciones e informes internos o entre órganos o entidades administrativas.

c) Relativas a información para cuya divulgación sea necesaria una acción previa de reelaboración.

d) Dirigidas a un órgano en cuyo poder no obre la información cuando se desconozca el competente.

e) Que sean manifiestamente repetitivas o tengan un carácter abusivo no justificado con la finalidad de transparencia de esta Ley.

38 En este sentido, el profesor José Luis Piñar Mañas, había puesto de manifiesto esta situación en "Seguridad, transparencia y protección de datos: el futuro de un necesario equilibrio", cit., pág. 14. "Debido a la no existencia en España de una legislación adecuada sobre el derecho de acceso a la información, están produciéndose situaciones muy cercanas a lo que sin duda es una instrumentalización de la protección de datos (sobre lo que ha llamado la atención el Defensor del Pueblo Europeo, 2001). Esta situación no es admisible. No facilitar el acceso a documentos o a informaciones en poder de las Administraciones públicas so pretexto de ser contrario a la Ley de Protección de Datos, encierra simplemente, en muchas ocasiones, la intención nada confesable de ocultar dicha información por pura conveniencia de quien dispone de ella, sin que se pueda invocar la LOPD. Ahora bien, también es cierto que la falta de una ley reguladora del acceso a la información impide en no pocas situaciones contar con la habilitación legal necesaria para ceder los datos que tal acceso pueda implicar. Habilitación que una ley facilitaría, en los términos regulados en ella. Puede verse también PIÑAR MAÑAS, J. L. "Transparencia y protección de datos: las claves de un equilibrio necesario", El gobierno local: estudios en homenaje al profesor Luis Morell Ocaña, RUIZ OJEDA, A. L. (Coord.). Madrid: lustel, 2010. 
En este sentido, la ley general de transparencia remite a la Ley Orgánica 15/1999, de 13 de diciembre, sobre Protección de datos de Carácter Personal (en adelante, LOPD) para distinguir entre datos susceptibles de especial protección, de aquellos otros que son meramente identificativos, estableciendo una regulación diferenciada en uno y otro caso. Así, para los datos especialmente protegidos del artículo 7.2 de la LOPD, solo se concederá el acceso previo consentimiento expreso y por escrito del afectado. Para los datos a los que se refiere el artículo 7.3 de la LOPD, o datos relativos a la comisión de infracciones penales o administrativas que no conllevasen la amonestación pública al infractor, el acceso sólo se podrá autorizar en caso de que se cuente con el consentimiento expreso del afectado o si aquél estuviera amparado por una norma con rango de Ley.

Si la solicitud no hiciera referencia a datos especialmente protegidos, el órgano al que se dirija la solicitud concederá el acceso previa ponderación suficientemente razonada del interés público en la divulgación de la información y los derechos de los afectados cuyos datos aparezcan en la información solicitada, en particular su derecho fundamental a la protección de datos de carácter personal.

Esta decisión debiera tomarla, en última instancia y previa interposición de la correspondiente reclamación prevista en el artículo 15 de la Ley 19/2013, de 9 de diciembre, el Consejo de la Transparencia y el Buen Gobierno. Es decir, es este órgano quien decidirá si prevalece el derecho a la protección de datos o el derecho de acceso a la información. Esta es una razón de peso para argumentar a favor de que sea la Agencia Española de protección de Datos quien asuma las funciones propias del órgano garante de la transparencia. No debemos olvidar que, como ha señalado el profesor José Luis PIÑAR MAÑAS en diversas ocasiones, estamos ante las dos caras de una misma moneda. ${ }^{39}$

\subsection{Tramitación del procedimiento y régimen de recursos administrativos}

Respecto a la tramitación del procedimiento, así como en relación al régimen del silencio administrativo, sí encontramos importantes diferencias en ambas regulaciones.

El plazo de subsanación en el caso de la Ley 27/2006, de 18 de julio, relativa al acceso a la información ambiental, es de 1 mes, con asistencia, en su caso, del órgano administrativo correspondiente. Sin embargo, en la Ley general de transparencia el plazo es de 10 días hábiles sin que se prevea ningún tipo de asistencia o ayuda al solicitante.

39 PIÑAR MAÑAS. J. L. “Transparencia y protección de datos: las claves de un equilibrio necesario”, cit. 
En cuanto al plazo de resolución y notificación, es igual en ambas leyes: 1 mes, ampliable a dos en el caso de un gran volumen de solicitudes o la especial complejidad de la solicitud.

Sí cambia, radicalmente, el régimen del silencio administrativo. En el caso de la Ley $27 / 2006$, de 18 de julio, no está regulado expresamente el sentido del silencio en el supuesto de que el órgano competente no resuelva y notifique en plazo la solicitud de información. Es por ello por lo que se aplica el régimen general del artículo 43 de la ley 30/1992, de 26 de noviembre, que considera, en estos casos, y a falta de regulación expresa, el silencio estimatorio o positivo. Bien es cierto que de poco valdrá dicha estimación por acto presunto si lo que se solicita es determinada información, pero, en cualquier caso, no está demás.

Sin embargo, la regulación establecida en la Ley 19/2013, de 9 de diciembre, de manera sorprendente establece que, transcurridos los plazos sin que el órgano competente haya resuelto y notificado la solicitud de acceso a la información, habrá de entenderse desestimada por silencio administrativo (artículo 20.4). Esta regulación de la Ley general de transparencia parece no haber tenido en cuenta la reforma de la Ley 30/1992, de 26 de noviembre, operada por la Ley 25/2009, de 22 de diciembre, mejor conocida como "Ley Ómnibus". ${ }^{40} \mathrm{Y}$ es que, como motivo de esta Ley, se modificó el artículo 43 de la ley 30/1992, en el sentido de que el establecimiento de un silencio negativo, como excepción a la regla general del silencio positivo, requería no solo venir reconocido expresamente en una norma con rango de Ley, sino que estuviera justificado en una razón imperiosa de interés general. ${ }^{41}$ El artículo 20.4 de la Ley de Transparencia establece un silencio negativo como excepción a la regla general del silencio positivo, sin embargo, no se justifica en ninguna razón imperiosa de interés general, lo que vulnera, en mi

40 Esta Ley 25/2009, de 22 de diciembre, de modificación de diversas leyes para su adaptación a la Ley sobre el libre acceso a las actividades de servicios y su ejercicio, junto con la Ley 17/2009, de 23 de noviembre, sobre el libre acceso a las actividades de servicios y su ejercicio, llevan a cabo la transposición en nuestro país de la bien conocida Directiva 2006/123/CE, de 12 de diciembre, relativa a los servicios en el mercado interior. Esta norma, en opinión de una buena parte de la doctrina, entre la que humildemente me encuentro, ha venido a revolucionar el Derecho Administrativo español, al menos en lo que se refiere a las técnicas de control.

41 Sobre el concepto de razón imperiosa de interés general, que se ha convertido en la clave de bóveda de todo el sistema de intervención administrativa, habrá que estar a lo que establece el artículo 4.8 de la Directiva de Servicios que lo define como: razón reconocida como tal en la jurisprudencia del Tribunal de Justicia, incluidas las siguientes: el orden público, la seguridad pública, la protección civil, la salud pública, la preservación del equilibrio financiero del régimen de seguridad social, la protección de los consumidores, de los destinatarios de servicios y de los trabajadores, las exigencias de la buena fe en las transacciones comerciales, la lucha contra el fraude, la protección del medio ambiente y del entorno urbano, la sanidad animal, la propiedad intelectual e industrial, la conservación del patrimonio histórico y artístico nacional y los objetivos de la política social y cultural. Se ve claramente que, pese a lo que ha interpretado el legislador español, es un numerus apertus, y habrá que estar a lo que, en cada caso concreto, establezca el Tribunal de Justicia de la Unión Europea. 
opinión, el Derecho de la Unión Europea. En concreto, la Directiva 2006/123/CE, del Parlamento Europeo y del Consejo, de 12 de diciembre, relativa a los servicios en el mercado interior.

También hay un cambio importante en cuanto al régimen de los recursos administrativos. Si en la ley sectorial sobre acceso a la información ambiental remite al régimen de recursos previsto en la Ley 30/1992, de 26 de noviembre, y por consiguiente, pondrán fin a la vía administrativa, o no, en función de lo establecido en el artículo 109 de la misma (véanse los artículos 10.2 in fine, puestos en relación con los artículos 20 y 21 de la Ley 26/2007, de 18 de julio). En la ley general de transparencia, por el contrario, la resolución sí pone fin a la vía administrativa, abriendo la vía jurisdiccional contenciosa o, en su caso, si así se decide, cabe interponer un recurso potestativo de reposición ante el Consejo de la Transparencia y Buen Gobierno (artículos 20.5 y 24).

\section{Conclusiones}

El derecho de acceso a la información es esencial en un Estado democrático, como el nuestro, para facilitar la participación de los ciudadanos en la vida política, social, económica y cultural. Esto, que es necesario con cualquier tipo de información, se hace imprescindible cuando hablamos de información medioambiental que puede afectar a la vida, salud e integridad física y moral de los ciudadanos.

El derecho de acceso a la información ambiental no está expresamente reconocido como derecho fundamental por nuestra Constitución. Tampoco por la Carta de Derechos Fundamentales de la Unión Europea ni por el Convenio de Derechos Humanos. Sin embargo, teniendo en cuenta la dimensión ambiental de los derechos fundamentales, nacida de la jurisprudencia del Tribunal Europeo de Derechos Humanos, el derecho de acceso a la información ambiental podría adquirir esta naturaleza, con el máximo rango, a poco que se pueda considerar afectada la salud, integridad física, privacidad o dignidad de los ciudadanos.

La Ley 27/2006, de 18 de julio, que regula el derecho de acceso a la información, la participación y el acceso a la justicia en materia ambiental, considera este derecho de acceso más como un principio de actuación que como un verdadero derecho fundamental. Por su parte, la reciente Ley 19/2013, de 9 de diciembre, de transparencia, acceso a la información y buen gobierno no ha venido a modificar mucho la situación anterior. Primero, porque solo se aplica al derecho de acceso a la información ambiental con carácter supletorio y, segundo, porque sigue considerando al derecho de acceso a la información ambiental como un mero derecho de configuración legal. Más como un principio de actuación de los poderes públicos que como un auténtico derecho fundamental. 
Pese a todo, en mi opinión, el derecho de acceso a la información en general, y a la ambiental en particular, acabará siendo reconocida como un derecho fundamental de los de más alto rango por la jurisprudencia, debemos reconocer que estamos en pleno proceso y aún queda un largo camino por recorrer.

\section{Access to environmental information in Spain after the new transparency law}

Abstract: After the publication in Spain of the transparency, access to information and good governance Law, the way to access to environmental information has not changed. We now have a general law, that I just mentioned, and a specific law (right of access to information, public participation and access to justice in environmental matters), which applies a priority. Both regulations have important differences that are analyzed in this paper.

Keywords: Transparency. Access to information. Environmental information. General law. Specific law. Comparative analysis.

Contents: 1 Introduction - $\mathbf{2}$ Introductory note on environmental law - $\mathbf{3}$ International legal framework on access to environmental information - 4 Recognition of the right of access to environmental information in European Union law - $\mathbf{5}$ Constitutional framework of the right of access to environmental information - 6 The right of access to environmental information after the publication of the new transparency law. Comparison of the regulations $\mathbf{-} \mathbf{7}$ Conclusions - References

\section{Referencias}

BOUAZZA ARIÑO, O. "Tribunal Europeo de Derechos Humanos: derechos frente a la contaminación, libertad de conciencia ambiental y protección urbanística del suelo". In: LÓPEZ RAMÓN, F. (Coord.). Observatorio de políticas ambientales 2013.

BOUAZZA ARIÑO, O. "Vías indirectas para la protección del medio ambiente". Revista de Administración Pública, n. 170, 2006.

BOUAZZA ARIÑO, O. “Constitutional Environnmental Rights”. Revista de Administración Pública, n. 169, 2006.

BOUAZZA ARIÑO, O. "Respeto a la vida privada y protección del medio ambiente en la jurisprudencia del Tribunal Europeo de Derechos Humanos". Revista de Administración Pública, n. 160, 2003.

DE SALES CAVEDóN, F. “La construcción de una dimensión ambiental de los derechos humanos por la jurisprudencia de la Corte Europea de Derechos Humanos: el derecho de acceso a la información y a la libertad de expresión en materia ambiental". Revista Aranzadi de derecho ambiental, n. 14, 2008. 
ESTEVE PARDO, J. La nueva relación entre Estado y Sociedad. Aproximación al trasfondo de la crisis. Madrid: Marcial Pons, 2013.

ESTEVE PARDO, J. El desconcierto del Leviatán. Madrid: Marcial Pons, 2009.

FERNÁNDEZ VALVERDE, R. "La integración de las exigencias del Convenio de Aarhus en el sistema procesal español a través de la Ley 27/2006", en LOZANO CUTANDA, B y GUTIERREZALVIZ CONRADI, F. (Dirs.). Examen de la nueva ley de acceso a la información, participación pública y acceso a la justicia en materia de medio ambiente, Estudios de Derecho Judicial, Madrid, Consejo General del Poder Judicial, n. 137, 2008.

LATORRE, A. Introducción al Derecho. Madrid: Ariel, 2008.

LOZANO CUTANDA, B. Derecho Ambiental Administrativo. 9. ed. Madrid: Dykinson, 2008.

MARTÍN RETORTILLO BAQUER, L. Vías concurrentes para la protección de los derechos humanos. Madrid: Civitas, 2006.

MARTÍN RETORTILLO BAQUER, L. La Europa de Ios Derechos Humanos. Madrid: Centro de Estudios Políticos y Constitucionales, 1998.

PIÑAR MAÑAS, J. L. "Transparencia y protección de datos: las claves de un equilibrio necesario", In: RUIZ OJEDA, A. L. (Coord.). El gobierno local: estudios en homenaje al profesor Luis Morell Ocaña. Madrid: Iustel, 2010.

PIÑAR MAÑAS, J. L. "La protección de datos". In: CANO CAMPOS, T. (Coord.). Lecciones y materiales para el estudio del derecho administrativo, v. 9. Madrid: lustel, 2009.

PIÑAR MAÑAS, J. L. en "Seguridad, transparencia y protección de datos: el futuro de un necesario equilibrio", Documento de Trabajo 147/2009, Fundación Alternativas, 2009.

PIÑAR MAÑAS, J. L. "El derecho a la protección de datos de carácter personal en la jurisprudencia del Tribunal de Justicia de las Comunidades Europeas", In: BADELL MADRID, R. (Coord.). Derecho contencioso-administrativo: libro homenaje al profesor Luis Henrique Farias Mata. Instituto de Estudios Jurídicos del Estado de Lara, 2006.

PIÑAR MAÑAS, J. L. "derecho fundamental a la protección de datos personales. Algunos retos de presente y futuro", Revista parlamentaria de la Asamblea de Madrid, n. 13, 2005.

PIÑAR MAÑAS, J. L. "derecho fundamental a la protección de datos personales. Algunos retos de presente y futuro", Revista parlamentaria de la Asamblea de Madrid, n. 13, 2005.

PIÑAR MAÑAS, J. L. (Coord.). Desarrollo sostenible y protección del medio ambiente. Madrid: Civitas, 2002. 
RAMS RAMOS, L. "La transformación del derecho de acceso en España: de derecho de configuración legal a derecho fundamental", Revista Española de Derecho Administrativo, n. 160, 2013.

SCHMIDT-ASSMAN, E. "La ciencia del Derecho Administrativo ante la internacionalización de las relaciones administrativas”. Revista de Administración Pública, Madrid, n. 171, 2006.

Recebido em: 12.11.2015

Aprovado em: 12.07.2016

Informação bibliográfica deste texto, conforme a NBR 6023:2002 da Associação Brasileira de Normas Técnicas (ABNT):

CORRAL SASTRE, Alejandro. El acceso a la información ambiental en España a la luz de la nueva Ley de Transparencia. Direitos Fundamentais \& Justiça, Belo Horizonte, ano 10, n. 34, p. 41-68, jan./jun. 2016. 